Article

\title{
Enhanced Piezoelectric Properties of Poly(Vinylidenefluoride-Co-Trifluoroethylene)/ Carbon-Based Nanomaterial Composite Films for Pressure Sensing Applications
}

\author{
Jia-Wun Li 1,+(D), Chen-Yang Huang ${ }^{1,+}$, Kuan-Yu Chen ${ }^{1,+}$, Jian-Xun Chen ${ }^{1}$, Xiao-Yong Hsu ${ }^{1}$, \\ Yan-Feng Chen ${ }^{1}$, Chung-Feng Jeffrey Kuo ${ }^{1}$, Chih-Chia Cheng ${ }^{2} \mathbb{D}$, Maw-Cherng Suen ${ }^{3}$ \\ and Chih-Wei Chiu ${ }^{1, * \text { iD }}$ \\ 1 Department of Materials Science and Engineering, National Taiwan University of Science and Technology, \\ Taipei 10607, Taiwan; a12352335@yahoo.com.tw (J.-W.L.); D10504015@mail.ntust.edu.tw (C.-Y.H.); \\ M10704205@mail.ntust.edu.tw (K.-Y.C.); ch60210@gmail.com (J.-X.C.); xyhsu.0879@ttri.org.tw (X.-Y.H.); \\ kk0960216886@gmail.com (Y.-F.C.); jeffreykuo@mail.ntust.edu.tw (C.-F.J.K.) \\ 2 Graduate Institute of Applied Science and Technology, National Taiwan University of Science and Technology, \\ Taipei 10607, Taiwan; cccheng@mail.ntust.edu.tw \\ 3 Department of Fashion Business Administration, Lee-Ming Institute of Technology, New Taipei City 24305, \\ Taiwan; sunmc0414@gmail.com \\ * Correspondence: cwchiu@mail.ntust.edu.tw; Tel.: +886-2-2737-6521; Fax: +886-2-2737-6544 \\ + These authors contributed equally to this work.
}

Received: 30 November 2020; Accepted: 14 December 2020; Published: 16 December 2020

check for updates

\begin{abstract}
In this study, heat and polarization treatments were applied to poly(vinylidenefluoride-co-trifluoroethylene (PVDF-TrFE) films to improve their crystallinity and piezoelectric effect. Carbon-based nanomaterials (CBNs) of multiple dimensions (i.e., modified zero-dimensional (OD) carbon black (OCB), one-dimensional (1D) modified carbon nanotubes (CNT-COOH) and two-dimensional (2D) graphene oxide (GO)) were added to the copolymer to study the effects of different CBN dimensions on the crystallinity and piezoelectric effect of PVDF-TrFE films. Additionally, amphiphilic polymeric dispersants were added to improve the dispersibility of CBNs; the dispersant was synthesized by the amidation, and imidization reactions of styrene-maleic anhydride copolymer (SMAz) and polyoxyalkylene amine (M1000). Polymer solutions with different ratios of CBN to dispersant $(z=10: 1,5: 1,1: 1,1: 5,1: 10)$ were prepared. The enhanced dispersibility enabled the fluorine atoms in the PVDF-TrFE molecular chain to more efficiently form hydrogen bonds with the-COOH group in the $\mathrm{CBN}$, thereby increasing the content of the $\beta$ crystal phase (the origin of the piezoelectric effect) of the film. Therefore, the resulting film exhibited a higher output voltage on the application side and better sensitivity on the sensing element. The addition of $\mathrm{CNT}-\mathrm{COOH}$ and polymeric dispersants increased the $\beta$-phase content in PVDF-TrFE from $73.6 \%$ to $86.4 \%$, which in turn raised the piezoelectric coefficient from $19.8 \pm 1.0$ to $26.4 \pm 1.3 \mathrm{pC} / \mathrm{N}$. The composite film-based pressure sensor also exhibited a high degree of sensitivity, which is expected to have commercial potential in the future.
\end{abstract}

Keywords: piezoelectric; poly(vinylidenefluoride-co-trifluoroethylene; carbon black; carbon nanotubes; graphene oxide

\section{Introduction}

Recent years have witnessed a consistent rise in public demand for electronic products [1], among which wearable devices have gained attention for their comfort, flexibility, and durability $[2,3]$. 
Meanwhile, in order to reduce global energy consumption, the development of alternative energy continues to gain traction [4]. The renewable energies currently under development include solar, thermal, wind, and kinetic energies [5,6]. Three methods are available for harvesting vibration energy, namely, electrostatic, electromagnetic, and piezoelectric methods [7]. The ceramic piezoelectric materials are generally characterized by high-voltage and high-dielectric properties. However, their applications are still limited because of various deficiencies. For example, they are too hard and brittle, difficult to process, and bio-incompatible [8]. Piezoelectric polymers, with advantages such as simple processing routes, light, and thin structures, durability, high chemical resistance, low environmental sensitivity, and biocompatibility, boast considerable potential in wearable devices [9]. Polyvinylidene (PVDF) [10] and poly(vinylidenefluoride-co-trifluoroethylene (PVDF-TrFE) [11] are among the materials that have attracted significant attention from the academic world in recent years because they are scratch-resistant, easy to process, and structurally light and thin [12]. The crystalline forms of both PVDF and PVDF-TrFE are composed of a combination of $\alpha$ - and $\beta$-phases; the $\alpha$-phase is most commonly seen in PVDF or its copolymers, but the $\beta$-phase is more important to the piezoelectric effect because the $\beta$-phase has both piezoelectric and electrothermal properties [13]. Additionally, the mechanism underpinning the induced $\alpha$ to $\beta$-phase transformation in PVDF and its copolymers has been widely studied [14-16]. Specific intermolecular forces (van der Waals forces, ion coupling, and hydrogen bonding) can be used to induce the $\alpha$ - to $\beta$-phase transformation in PVDF and its copolymer [17-19].

For example, Shuai [20] and Bhavanasi et al. [21] respectively used oxygen-containing groups on the surface of graphene oxide and hydrogen bonding between PVDF-TrFE to induce the crystallization of the ferroelectric $\beta$-phase, which exhibited good performance in electrical output and energy harvesting devices. In terms of piezoelectric efficiency, although PVDF has a higher piezoelectric coefficient $\left(\mathrm{d}_{33}\right.$, 20-28 pC/N) than PVDF-TrFE. Levi et al. [22] nevertheless showed that, compared with PVDF, the use of the PVDF-TrFE copolymer could more effectively facilitate the dispersion of nanocarbon materials in solution. Meanwhile, the interaction between the functional groups on the surface of the nanomaterial and PVDF (or its copolymers) can be harnessed to promote the $\beta$-phase [23], thereby improving the crystallinity and piezoelectric properties of PVDF (or its copolymers). In our laboratory, we have comprehensively studied the dispersion and stabilization of inorganic nanomaterials by polymeric dispersants [24-27]; the molecular structure of the polymeric dispersant has been used to interact with the inorganic nanomaterial via $\pi-\pi$ stacking and lone pair interactions, thereby enhancing the dispersion and stability of the inorganic nanoparticle in solution. To our knowledge, no research has discussed the seismocardiography influence of carbon nanomaterials of different dimensions on piezoelectric polymers. Previously reported [28] using nonlocal continuum methods to evaluate the structural behavior of nano-sensors and nano-actuators on nano-beams such as strain gradient method and stress driven theory. The models provide a stiffening structural behavior based on experimental evidence [29].

In this study, oxidized carbon black (OCB) with carboxylic acid or hydroxyl groups on the surface, modified carbon nanotubes (CNT-COOH), and graphene oxide (GO) were added to the PVDF-TrFE solution in different weight ratios, after which a composite piezoelectric film of carbon nanomaterial/PVDF-TrFE (nanocarbon/PVDF-T) was prepared. The addition of carbon nanomaterials can induce a higher proportion of the $\beta$-phase structure and improve the overall piezoelectricity and mechanical strength of the film. As the high surface energy of the nanoparticles may cause agglomeration and therefore worsen the resultant properties of the material, styrene maleic acid-amide (SMA-amide) was added as a dispersant to improve the dispersion of the modified carbon nanotubes in the PVDF-TrFE solution; better piezoelectric effects were generated by improving the dispersion of the carbon materials in the film. Finally, the composite film was applied in seismocardiography (SCG) physiological signal sensors, pressure sensors, and energy harvesting devices. 


\section{Experimental}

\subsection{Materials}

Poly(vinylidenefluoride-co-trifluoroethylene $\left(\mathrm{PVDF}-\mathrm{TrFE}, \mathrm{Tc}=127.4^{\circ} \mathrm{C}, \mathrm{Tm}=148.8^{\circ} \mathrm{C}\right.$ ) was procured from Piezotech (Pierre-Benite, France). Carbon black (CB, particle size $40 \mathrm{~nm}$ ) and oxidized carbon black (OCB, oxygen content $\sim 20 \%$, particle size $40 \mathrm{~nm}$ ) were purchased from MTI Japan (Yokohama). Multi-walled carbon nanotubes (CNT, diameter 10-20 nm), carboxyl group enriched multi-walled carbon nanotubes (CNT-COOH, diameter 10-20 nm, oxygen content $25 \%$ ), reduced graphene oxide (rGO, diameter $550 \mathrm{~nm}$, oxygen content $4 \sim 7 \%$ ), and graphene oxide powder (GO, film diameter $550 \mathrm{~nm}$, oxygen content $50 \%$ ) were purchased from Conjutek Ltd (Taipei, Taiwan). Styrene maleic anhydride (SMA 1000, SMA 2000, SMAEF 40, SMAEF 80) was purchased from Yuang Hong Corp. (Taipei, Taiwan) and Jeffamine M1000 (M1000) was procured from Huntsman Corporation (Salt Lake City, UT, USA).

\subsection{Preparation of Carbon Nanomaterial/Poly(Vinylidenefluoride-Co-Trifluoroethylene) Composite Piezoelectric Film}

Methyl ethyl ketone (MEK) was added to reduce the boiling point of the solvent; thus, the solvent could be completely volatilized below the melting point of PVDF-TrFE. PVDF-TrFE with a weight concentration of $20 \mathrm{wt} \%$ was then added to the solvent, and the mixture was stirred with a heated stirrer at $50^{\circ} \mathrm{C}$ for $2 \mathrm{~h}$ to ensure dissolution; thus a PVDF-TrFE solution was obtained. Then, the carbon material was added in different concentrations with respect to the solvent $(0.1 \mathrm{wt} \%, 0.5 \mathrm{wt} \%, 1 \mathrm{wt} \%, 3 \mathrm{wt} \%$, or $5 \mathrm{wt} \%$ ). The mixture was ultrasonicated for $20 \mathrm{~min}$ to physically disperse the carbon nanomaterials. The dispersed material was then added to a pre-configured PVDF-TrFE solution to prepare a carbon nanomaterial/PVDF-TrFE (nanocarbon/PVDF-T) solution. Next, the nanocarbon/PVDF-T solution was wet coated onto a high-temperature resistant glass, placed in a vacuum oven for defoaming, and then dried at $80^{\circ} \mathrm{C}$ for $2 \mathrm{~h}$ to completely evaporate the solvent, producing a nanocarbon/PVDF-T composite film of approximately $80 \mu \mathrm{m}$ in thickness. At this stage, the film mostly contained the $\alpha$-phase, which does not have piezoelectric properties (i.e., an absence of the piezoelectric effect). Subsequent annealing and polarization treatments were needed to transform the $\alpha$-phase into the $\beta$-phase, which has piezoelectric characteristics. Therefore, the nanocarbon/PVDF-T composite film was placed in a vacuum oven at various temperatures of an annealing process for $4 \mathrm{~h}$. Next, the annealed film was coated with silver glue on both sides to add the conductive layers. The film was then placed in a vacuum oven for $1 \mathrm{~h}$ until the solvent in the silver glue completely evaporated. The film was then taken out and polarized at a temperature of $50^{\circ} \mathrm{C}$ under different high-voltage electric fields for $2 \mathrm{~h}$ to finalize the preparation for the nanocarbon/PVDF-T composite piezoelectric film.

\subsection{Synthesis of Styrene Maleic Anhydride (SMA)-Amide}

SMA-amide was synthesized based on the practice previously adopted in the laboratory [30]. Four types of styrene maleic anhydride copolymers (SMAz; z =1000, 2000, EF40, EF80) with different benzene ring numbers were used in an amination grafting reaction with polyether monoamine (M1000, polyetheramine) in a molar ratio of $1: 1$ at $25{ }^{\circ} \mathrm{C}$ with tetrahydrofuran (THF) as the organic solvent, from which the star-shaped oil-soluble dispersant styrene maleic acid-amide (SMAz-M) was generated. First, a $50 \mathrm{~mL}$ three-necked round-bottom flask was fitted with a magnetic stirrer, nitrogen inlet/outlet tube, and a thermometer as the experimental instruments; 0.005 mol of SMAz ( $z=1000,2000, E F 40$, EF80) was added to $5 \mathrm{~mL}$ of THF. Then, $5 \mathrm{~mL}$ of THF containing $0.005 \mathrm{~mol}$ of M1000 was prepared, and the solution was titrated into the round bottom flask through a funnel. The mixture was vigorously stirred and kept at $25^{\circ} \mathrm{C}$ for $4 \mathrm{~h}$ and then heated to $80^{\circ} \mathrm{C}$ for $4 \mathrm{~h}$ for the reaction. Finally, the THF solvent was volatilized to obtain SMAz-M ( $z=1000,2000, \mathrm{EF} 40, \mathrm{EF} 80)$. 


\subsection{Preparation of Composite Piezoelectric Film with Modified Carbon Nanotube Dispersion}

The four dispersants, SMAz-M ( $\mathrm{z}=1000,2000, \mathrm{EF} 40, \mathrm{EF} 80)$, were added to disperse the modified carbon nanotubes (CNT-COOH) and to achieve improved stability in solution. The carbon nanomaterial $(0.005 \mathrm{~g})$ was added to the 1:1 DMF:MEK co-solvent $(5 \mathrm{~g})$, and the mixture was ultrasonicated for $20 \mathrm{~min}$. The nanocarbon material was completely dispersed in the solution after the mixture was stirred for $10 \mathrm{~min}$ in an ultrasonic cell crusher. Then, SMAz-M was added in the weight ratio (nanocarbon material:SMAz-M) of 10:1, 5:1, 1:1, 1:5, and 1:10, and a heated stirrer was used to stir the mixture at $50^{\circ} \mathrm{C}$ for $2 \mathrm{~h}$ to evenly mix the modified carbon nanotube dispersion with the PVDF-TrFE solution to achieve good dispersibility. After stirring, the modified carbon nanotube/PVDF-T solution will generate tiny bubbles in the solution. To avoid the generation of pores in the subsequent production of the film, which will affect the crystallinity and piezoelectric effect, the solution was ultrasonically shaken and then placed in a vacuum oven for defoaming so that the pores were inhibited during the film formation process.

\subsection{Characterization and Instruments}

X-ray diffraction (XRD; D2 Phaser, Bruker, Karlsruhe, Germany) was used to characterize PVDF-TrFE (after the annealing treatment at different temperatures, a polarization treatment at different voltage) and to analyze the crystallinity of the (OCB, CNT-COOH, GO)/PVDF-T composite piezoelectric film. The sample was cut to a size of $3 \mathrm{~cm} \times 3 \mathrm{~cm}$ and placed in a vacuum oven. When it was completely dried, testing was then conducted ( $\theta$ range: $10-50^{\circ}, 0.5 \mathrm{~s}$ for each point). Fourier transform infrared spectroscopy (FTIR; FTS-1000, Digilab, Hopkinton, MA, USA) was used to identify the functional groups of the carbon material before and after modification and to calculate the percentage of the $\beta$-phase of the composite piezoelectric film. The nanocarbon powder and piezoelectric composite material were placed on a contact platform and scanned within the range $400-4000 \mathrm{~cm}^{-1}$ at a resolution of $2 \mathrm{~cm}^{-1}$. Differential scanning calorimetry (DSC; DSC 6000, Perkin Elmer, Waltham, MA, USA) was used to characterize the thermal properties of the materials. The sample was packaged in an aluminum tray with a lid, heated to $180{ }^{\circ} \mathrm{C}$ to eliminate the thermal history, then cooled to $60{ }^{\circ} \mathrm{C}$ at a rate of $-10^{\circ} \mathrm{C} / \mathrm{min}$, and finally heated to $180^{\circ} \mathrm{C}$ at a rate of $10^{\circ} \mathrm{C} / \mathrm{min}$ where the second heating thermogram was recorded. The cross-section of the piezoelectric composite material was frozen in liquid nitrogen to fix its structure. Then, the sample was cut in half and plated with platinum before it was placed under a high-resolution field-emission scanning electron microscope (FESEM; JSM-6500F, JEOL, Tokyo, Japan). A UV-Visible spectrophotometer (UV-Vis; V-630, Jasco Corp., Kyoto, Japan)) was used to measure the dispersibility of the modified carbon nanotubes (CNT-COOH) in SMAz-M ( $z=1000,2000$, EF40, EF80) at $550 \mathrm{~nm}$. A transmission electron microscope (TEM; EM 902A, Zeiss, Oberkochen, Germany) was used to identify the dispersion at different ratios $(10: 1,5: 1,1: 1,1: 5,1: 10)$ of the modified carbon nanotubes (CNT-COOH) to SMAz-M ( $\mathrm{z}=1000,2000, \mathrm{EF} 40, \mathrm{EF} 80)$. The sample solution was dripped onto the carbon-plated copper mesh at a weight concentration of $0.01 \mathrm{wt} \%$ before it was placed in an oven to completely evaporate the solvent, and the resulting sample was examined for the dispersion of the nanocarbon material. For the voltage test, a universal tensile machine (MTS-370, MTS Systems Corp., Eden Prairie, MN, USA) equipped with a compression clamp was employed. The sample was cut into a voltage test pressure sheet with a diameter of $30 \mathrm{~mm}$ and then placed between the upper and lower clamps with a configuration of $200 \mathrm{~N}, 300 \mathrm{~N}$, and $400 \mathrm{~N}$ with the frequency set to one per second; when the sample was pressed, an oscilloscope (PicoScope 4224, Pico Technology Ltd., Cambridgeshire, UK) was used to receive the voltage value generated by the composite piezoelectric film. Contact angle measurements, performed using deionized water on samples, were recorded using a Sindatek instrument (model 100SB, Sindatek Instruments Co. Ltd., New Taipei, Taiwan) at room temperature. Raman spectra were recorded and integrated with a HORIBA iHR550 Raman microscope system (Protrustech Corp. Ltd., Tainan, Taiwan), and the light detection used a silicon CCD camera. It was focused via a $50 \times$ objective lens (Olympus BX-41) onto the sample with a laser operating at $\lambda=532 \mathrm{~nm}$. 


\section{Results and Discussion}

3.1. Poly(vinylidenefluoride-co-trifluoroethylene (PVDF-TrFE) Annealing Process and Polarization Treatment

The main aim of this study was to use the carboxylic acid or hydroxyl groups on the surface of $\mathrm{OCB}, \mathrm{CNT}-\mathrm{COOH}$, and GO to form hydrogen bonds with the fluorine element in the PVDF-TrFE film to induce the formation of the $\beta$-phase structure, as depicted in Figure 1. As a result of this process, the PVDF-TrFE piezoelectric films containing the carbon nanomaterials were superior to the original film in terms of piezoelectric properties. Therefore, it was necessary to identify the best processing conditions for the PVDF-TrFE piezoelectric film.
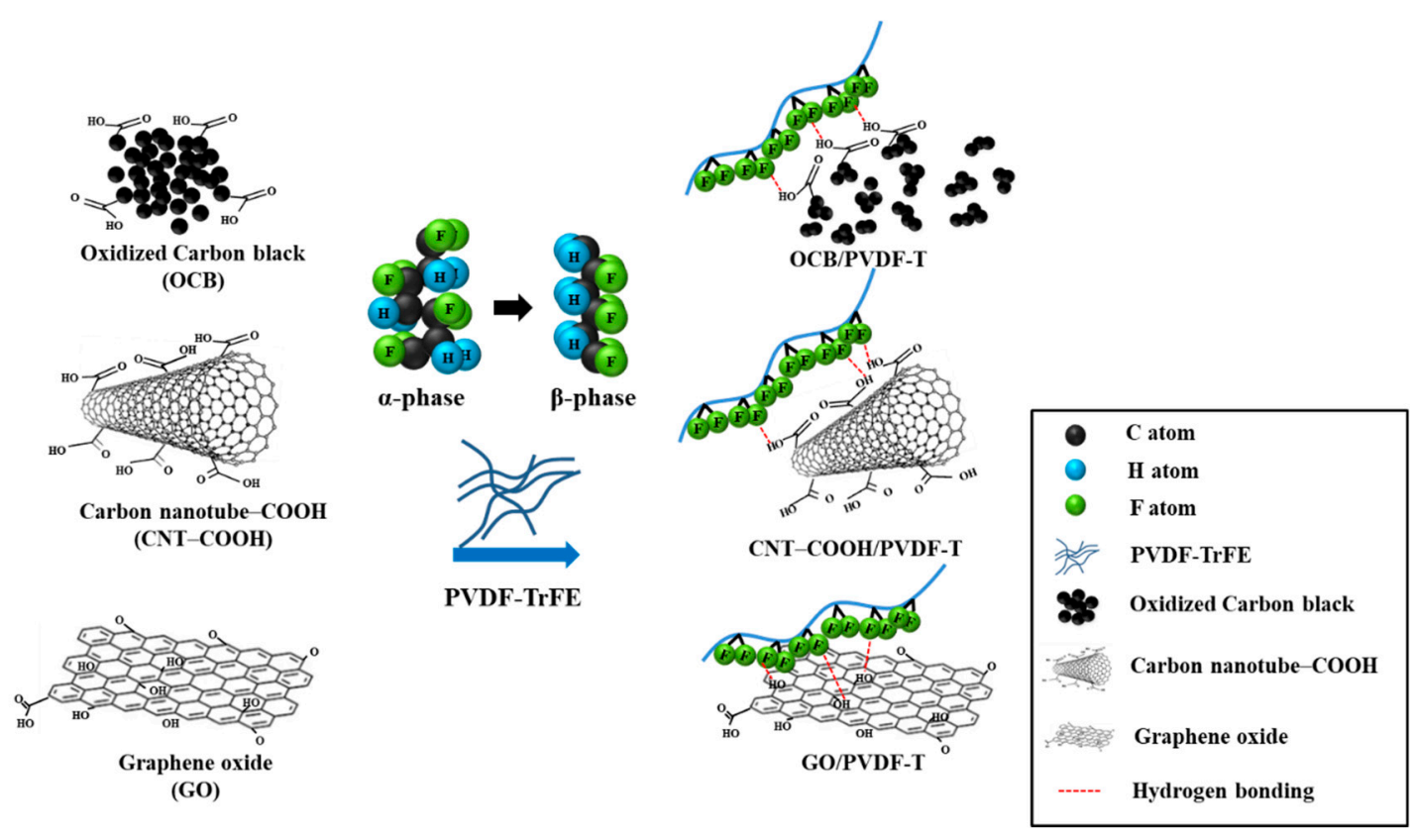

Figure 1. The schematic of carbon nanomaterials inducing the transformation of the $\alpha$-phase to $\beta$-phase of PVDF-TrEE.

First, the original PVDF-TrFE film was annealed. As shown in Figure 2a, after the PVDF-TrFE film was annealed at $125^{\circ} \mathrm{C}$ and $145^{\circ} \mathrm{C}$, the exterior of the film gradually changed from a transparent film to an opaque film. This is because the PVDF-TrFE molecular chain structure was transformed from the $\alpha$-phase to the $\beta$-phase. Then, XRD and FTIR were used to calculate the changes in the crystallinity of PVDF-TrFE annealed at different temperatures, as shown in Figure 2b,c. From the XRD patterns, it can be seen that when the annealing temperature reached $145^{\circ} \mathrm{C}$, the crystallinity of the PVDF-TrFE film gradually increased, and when the temperature increased to $155^{\circ} \mathrm{C}$, the crystallinity of the film significantly decreased. This is because the temperature of the annealing process usually needs to be above the recrystallization temperature $(\mathrm{Tc})$ and below the melting temperature $(\mathrm{Tm})$ of the film, and the annealing temperature exceeded the melting point of PVDF-TrFE $\left(\operatorname{Tm}=155^{\circ} \mathrm{C}\right)$, which significantly reduced the crystallinity. 
(a)
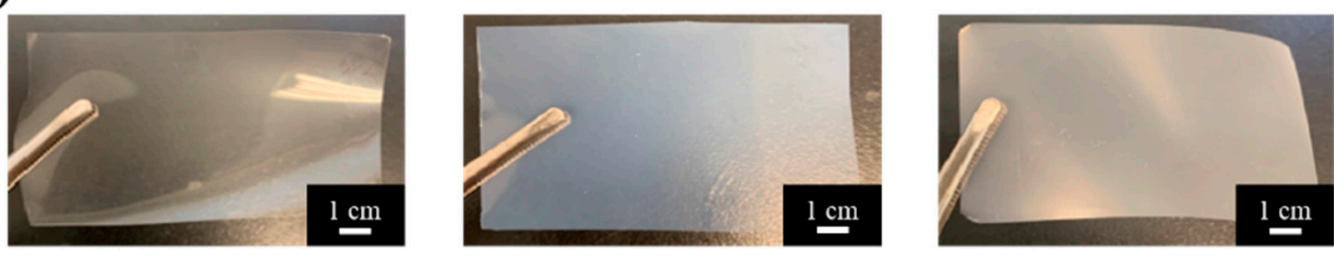

Before annealing

(b)

Annealing at $125^{\circ} \mathrm{C}$

Annealing at $145^{\circ} \mathrm{C}$

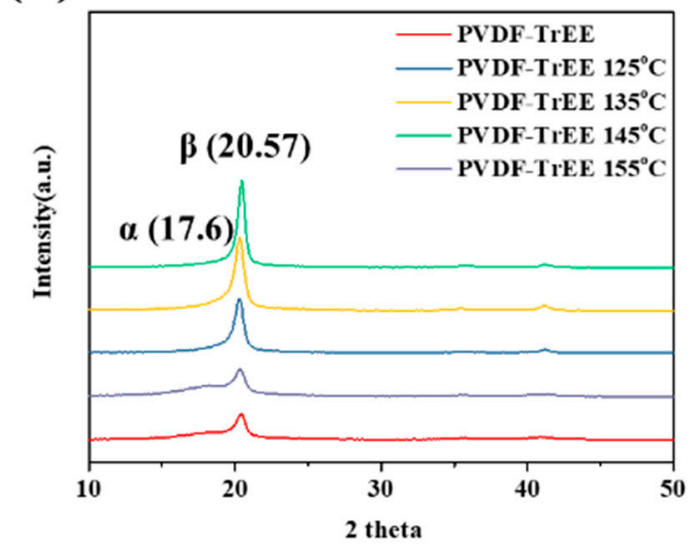

(c)

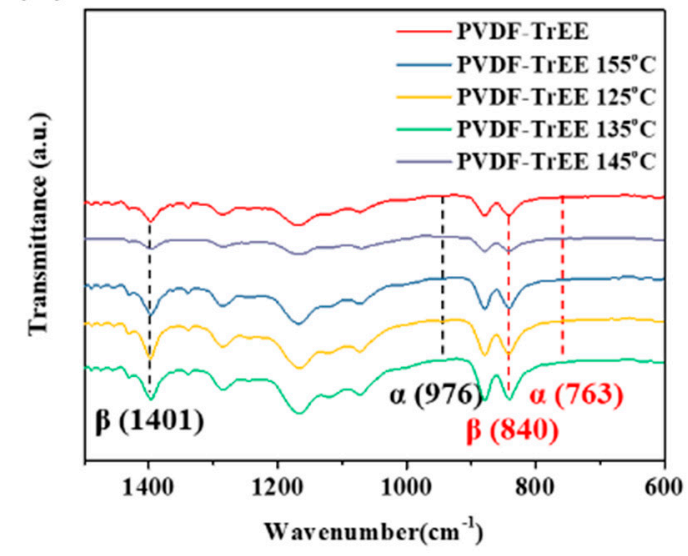

Figure 2. (a) Appearance, (b) XRD patterns, and (c) FTIR curves of PVDF-TrEE after different annealing temperatures.

The $\beta / \beta_{0}$ and crystallinity of PVDF-TrFE after annealing at different temperatures was then calculated, as shown in Table 1. Compared to the original state, the crystallinity of untreated PVDF-TrFE increased from $56.8 \%$ to $71.9 \%$ after annealing at $145{ }^{\circ} \mathrm{C}$, and the area of the $\beta$-phase peak at $2 \theta=20.57^{\circ}$ increased by $131.7 \%$; importantly, the $\alpha$-phase peak at $2 \theta=17.6^{\circ}$ disappeared after annealing. The FTIR spectra showed that the characteristic peaks of the $\alpha$-phase occurred at the wavelengths of $763 \mathrm{~cm}^{-1}$ and $976 \mathrm{~cm}^{-1}$, and the characteristic peaks of the $\beta$-phase occurred at $840 \mathrm{~cm}^{-1}$ and $1401 \mathrm{~cm}^{-1}$. The crystallinity of the $\beta$-phase $\left(\mathrm{F}_{(\beta)}\right)$ can be calculated by using the Beer-Lambert Law as expressed in Equation (1):

$$
\mathrm{F}_{\beta}=\frac{\mathrm{A}_{\beta}}{\left(\frac{\mathrm{K}_{\beta}}{\mathrm{K}_{\alpha}}\right) \mathrm{A}_{\alpha}+\mathrm{A}_{\beta}}=\frac{\mathrm{A}_{\beta}}{1.3 \mathrm{~A}_{\alpha}+\mathrm{A}_{\beta}}
$$

where $K_{\alpha}$ and $K_{\beta}$ are the molar area coefficients of the PVDF-TrFE film, which are $6.1 \times 10^{4} \mathrm{~cm}^{2} \mathrm{~mol}^{-1}$ and $7.7 \times 10^{4} \mathrm{~cm}^{2} \mathrm{~mol}^{-1}$, respectively; $A_{\alpha}$ is the area of the characteristic peak of the $\alpha$-phase at $763 \mathrm{~cm}^{-1}$; and $A_{\beta}$ is the area of the characteristic peak of the $\beta$-phase at $840 \mathrm{~cm}^{-1}$. The calculation results are summarized in Table 1 , which shows that annealing at $145^{\circ} \mathrm{C}$ increased the crystallinity of the $\beta$-phase from $62.1 \%$ to $69.5 \%$, while the crystallinity of the $\beta$-phase decreased to $55.6 \%$ when the melting point of PVDF-TrFE was exceeded, which is consistent with the XRD analysis results. Similarly, the decrease in the transparency of the film as the annealing temperature approached $145^{\circ} \mathrm{C}$ (Figure 2a) can be attributed to the gradual rise in the crystallinity of the film. Overall, the results revealed that annealing at $145{ }^{\circ} \mathrm{C}$ produced the greatest increase in the crystallinity of the film. Subsequently, the PVDF-TrFE film was polarized by the hot electrode method to increase the crystallinity. A positive voltage was applied to one side of the film, which was then placed on a conductive platform connected to a negative voltage, and high voltages of different values were applied to the film at $50{ }^{\circ} \mathrm{C}$. High voltages of 1000 , $2000,3000,4000$, and $5000 \mathrm{~V}$ were applied at $50^{\circ} \mathrm{C}$ to observe the changes in the crystallinity of the 
PVDF-TrFE film, as shown in Figure S1a. The crystallization calculations are summarized in Table 1; the results revealed that with increasing voltage, the $\beta$-phase crystallinity percentage of the PVDF-TrFE film gradually increased, but the $\beta$-phase crystallinity of the film at $5000 \mathrm{~V}$ and $4000 \mathrm{~V}$ did not increase significantly. A further examination of the hysteresis curve of the PVDF-TrFE film after annealing at $145^{\circ} \mathrm{C}$ (as shown in Figure S1b) shows that the curve converged at approximately $50 \mathrm{~V} / \mu \mathrm{m}$. Given that the film thickness of the PVDF-TrFE film was $80 \mu \mathrm{m}$, calculations show that the PVDF-TrFE film only needed approximately $4000 \mathrm{~V}(50 \mathrm{~V} / \mu \mathrm{m})$ to achieve polarization of the dipole moments. Therefore, to avoid the electrical breakdown caused by excessive voltage, which could lead to defects on the surface of the material and thus affect the piezoelectric effect of the film, a relatively low voltage $(4000 \mathrm{~V})$ was selected for subsequent polarization experiments. Finally, the piezoelectric coefficient $\left(\mathrm{d}_{33}\right)$ in the z-axis direction was recorded for the untreated PVDF-TrFE film, the PVDF-TrFE film annealed at $145^{\circ} \mathrm{C}$, and the PVDF-TrFE film annealed at $145^{\circ} \mathrm{C}$ and polarized at $4000 \mathrm{~V}$; these results are summarized in Table 1. The best reference data for the piezoelectric effect of most piezoelectric materials were $\mathrm{d}_{33}$, which refers to the Coulombs of current generated per Newton force. After the film was annealed and polarized, the application of $1 \mathrm{~N}$ force along the z-axis should generate a current of $19.8 \pm 1.0^{\circ} \mathrm{C}$. The results showed that the annealing treatment did not significantly improve the piezoelectric coefficient; however, the piezoelectric coefficient of the film improved significantly after the polarization treatment. This is because the dipole moments of the film were non-directionally arranged before polarization and canceled each other, whereas after the polarization treatment, the dipole moments were arranged in a consistent direction; therefore, voltage was generated when the film was subjected to an external force.

Table 1. Measurement results of the crystallinity, $\beta$-phase percentage, and piezoelectric coefficient of PVDF-TrEE after different annealing and polarization treatments.

\begin{tabular}{cccccccccc}
\hline $\begin{array}{c}\text { Sample } \\
\text { Name }\end{array}$ & PVDF-TrFE & $\begin{array}{c}\text { PVDF-TrFE } \\
\mathbf{1 3 5}{ }^{\circ} \mathbf{C}\end{array}$ & \multicolumn{3}{c}{ PVDF-TrFE 145 ${ }^{\circ} \mathbf{C}$} & & $\begin{array}{c}\text { PVDF-TrFE } \\
\mathbf{1 5 5}{ }^{\circ} \mathbf{C}\end{array}$ \\
\hline $\begin{array}{c}\text { Applied } \\
\text { voltage (V) }\end{array}$ & 0 & 0 & 0 & 1000 & 2000 & 3000 & 4000 & 5000 & 0 \\
$\quad \beta / \beta_{0}$ & - & $91.1 \%$ & $131.7 \%$ & - & - & - & - & - & $23.9 \%$ \\
Crystallinity & $56.8 \%$ & $70.4 \%$ & $71.9 \%$ & - & - & - & - & - & $61.8 \%$ \\
F( $(\beta)$ & $62.1 \%$ & $66.8 \%$ & $69.5 \%$ & $70.4 \%$ & $70.8 \%$ & $71.3 \%$ & $73.6 \%$ & $73.6 \%$ & $55.6 \%$ \\
d33 (pC/N) & $1.8 \pm 0.6$ & - & $2.3 \pm 0.8$ & - & - & - & $19.8 \pm 1.0$ & - & - \\
\hline
\end{tabular}

\subsection{Carbon Nanomaterials/PVDF-TrFE Piezoelectric Composite Film}

To facilitate the $\alpha$ - to $\beta$-phase transformation of PVDF-TrFE, inorganic substances containing functional groups were incorporated into the polymer matrix. In this study, the hydrogen bond between the fluorine atoms of PVDF-TrFE and the hydrogen atoms of the carboxylic acid or hydroxyl groups on the surface of the inorganic substance were leveraged to induce PVDF-TrFE to form more $\beta$-phases. As shown in Figure S2, when the inorganic carbon nanomaterials were oxidized, their -OH and $-\mathrm{COOH}$ functional groups increased significantly, thereby increasing the probability of $\beta$-phase formation. On the other hand, to avoid significant changes in the annealing temperature after the inorganic substances were added to PVDF-TrFE, Figure S3 shows the DSC graphs of PVDF-TrFE mixed with different oxidized nanocarbon materials. As shown in Figure S3, when PVDF-TrFE was mixed with oxidized carbon nanomaterials of different dimensions, the crystallization temperature remained at approximately $127^{\circ} \mathrm{C}$, and the melting point was maintained within the range of $149-152^{\circ} \mathrm{C}$; therefore, the annealing temperature was maintained below $145^{\circ} \mathrm{C}$, at which the PVDF-T composite film was annealed. Subsequently, the results indicated that the melting enthalpy $(\Delta \mathrm{Hc})$ of PVDF- $\operatorname{TrFE}$, OCB/PVDF-T $5 \mathrm{wt} \%$, CNT-COOH/PVDF-T $5 \mathrm{wt} \%$, and GO/PVDF-T $5 \mathrm{wt} \%$ were 21.6, 22.5, 34.5, and $25.6 \mathrm{~J} / \mathrm{g}$ after calculating the melting enthalpy, indicating that the crystallinity of PVDF-TrFE can be effectively improved when carbon nanomaterials are added to PVDF-TrFE. Figure 3a-c shows the XRD patterns of the nanocarbon/PVDF-T composite films with different dimensions and different 
addition amounts of the carbon nanomaterial, and the calculations of crystallinity are shown in Table 2. The results demonstrate that with $1 \mathrm{wt} \% \mathrm{OCB}$, the film crystallinity reached $83.1 \%$, and with $3 \mathrm{wt} \%$ $\mathrm{OCT}$, the crystallinity decreased; in the CNT-COOH system, with $1 \mathrm{wt} \%$ addition, the film crystallinity reached $83.4 \%$, and with $3 \mathrm{wt} \%$ addition, the crystallinity decreased; in the GO system, with $3 \mathrm{wt} \%$ addition, the degree of film crystallinity reached $76.6 \%$, and with $5 \mathrm{wt} \%$ addition, the crystallinity decreased. This may be because an excessive concentration of the carbon material deteriorates the polymer matrix or decreases the dispersibility of the nanomaterial. In addition, the optimal addition amount of OCB and CNT-COOH was found to be $1 \mathrm{wt} \%$, while that of GO was $3 \mathrm{wt} \%$. This difference in the optimal amount may arise from the difference in the oxygen content of the carbon nanomaterials. For OCB and CNT, the oxygen content of $-\mathrm{COOH}$ was respectively $20 \%$ and $25 \%$, while the oxygen content of GO was as high as $50 \%$. Therefore, when GO was mixed into PVDF-TrFE, the greater number of $-\mathrm{OH}$ and $-\mathrm{COOH}$ functional groups on the surface of $\mathrm{GO}$ produced more hydrogen bonds with fluorine atoms, resulting in a good dispersion effect at higher concentrations. Figure $3 \mathrm{~d}-\mathrm{f}$ shows the FTIR spectra of the nanocarbon/PVDF-T composite films of different dimensions and different additions of the carbon nanomaterial. The characteristic peaks of the $\alpha$ - and $\beta$-phases were observed in all the spectra.

Despite the continuous efforts invested in seeking optimal parameters, as shown in Figure 4, it is nevertheless difficult to avoid the agglomeration of trace inorganic substances without the addition of any dispersant because of the intrinsic properties of inorganic substances. This kind of micro-agglomeration slightly affects the piezoelectric properties of the piezoelectric film. Therefore, this study adopted the previous practice of the laboratory to synthesize SMA-M dispersants and added them to the $1 \mathrm{wt} \% \mathrm{CNT}-\mathrm{COOH} / \mathrm{PVDF}-\mathrm{T}$ solution, in the hope that the piezoelectric performance can be further improved.

(a)

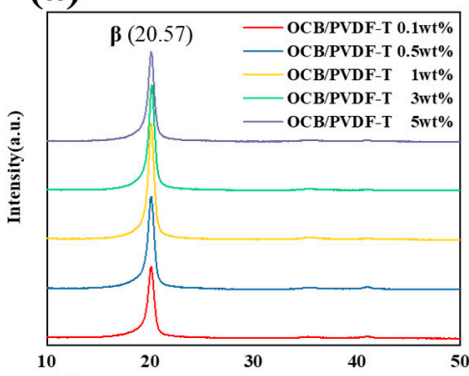

(d)

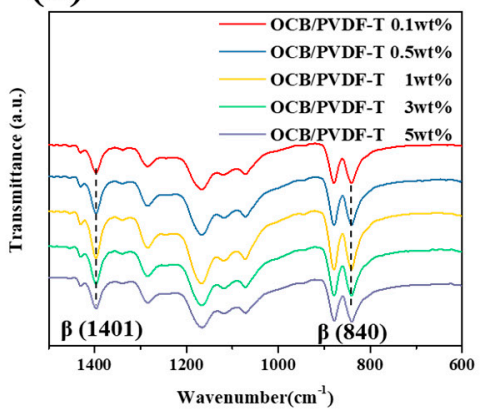

(b)
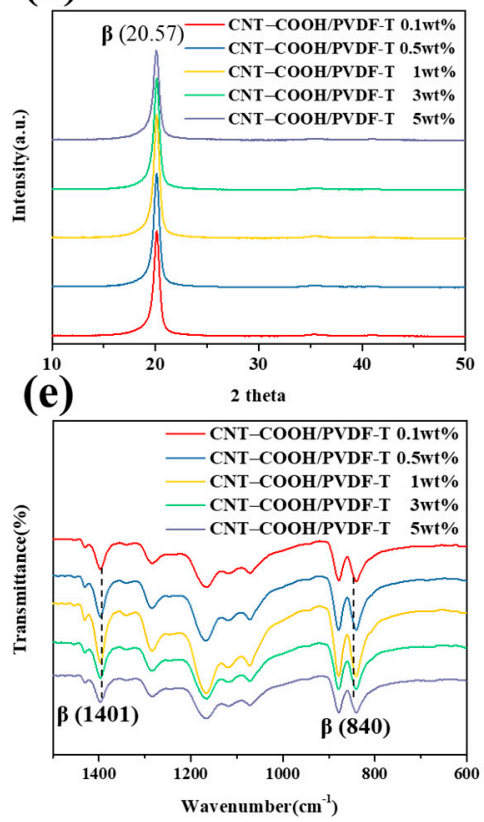

(c)
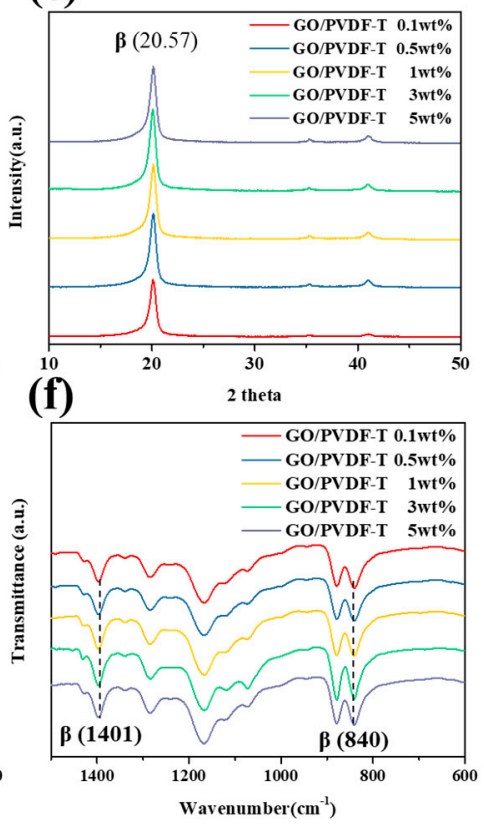

Figure 3. $(\mathbf{a}-\mathbf{c})$ XRD and (d-f) FTIR curves of PVDF-TrEE with different ratios of OCB, CNT-COOH, and GO. 
Table 2. Measurement results of the crystallinity, $\beta$-phase percentage, and piezoelectric coefficient of nanocarbon/PVDF-T.

\begin{tabular}{|c|c|c|c|c|c|}
\hline Sample & Dispersant & Content (wt\%) & Crystallinity (\%) & $F(\beta)(\%)$ & $d_{33}(p C / N)$ \\
\hline \multirow{5}{*}{ OCB/PVDF-TrFE } & - & 0.1 & 78.9 & 74.4 & - \\
\hline & - & 0.5 & 80.6 & 79.6 & - \\
\hline & - & 1.0 & 83.1 & 80.9 & $23.2 \pm 1.4$ \\
\hline & - & 3.0 & 82.4 & 78.3 & - \\
\hline & - & 5.0 & 81.2 & 74.3 & - \\
\hline \multirow{9}{*}{ CNT-COOH/PVDF-TrFE } & - & 0.1 & 82.1 & 75.2 & - \\
\hline & - & 0.5 & 82.9 & 77.9 & - \\
\hline & - & 1.0 & 83.4 & 82.8 & $24.3 \pm 1.3$ \\
\hline & SMA 1000 & 1.0 & 83.5 & 84.2 & - \\
\hline & SMA 2000 & 1.0 & 83.6 & 85.1 & - \\
\hline & SMA EF40 & 1.0 & 83.8 & 86.4 & $26.4 \pm 1.3$ \\
\hline & SMA EF80 & 1.0 & 83.4 & 84.5 & - \\
\hline & - & 3.0 & 81.8 & 76.6 & - \\
\hline & - & 5.0 & 79.7 & 74.7 & - \\
\hline \multirow{5}{*}{ GO/PVDF-TrFE } & - & 0.1 & 73.0 & 74.8 & - \\
\hline & - & 0.5 & 75.2 & 75.7 & - \\
\hline & - & 1.0 & 75.4 & 76.5 & - \\
\hline & - & 3.0 & 76.6 & 77.3 & $20.6 \pm 1.3$ \\
\hline & - & 5.0 & 75.5 & 76.8 & - \\
\hline
\end{tabular}

(a)

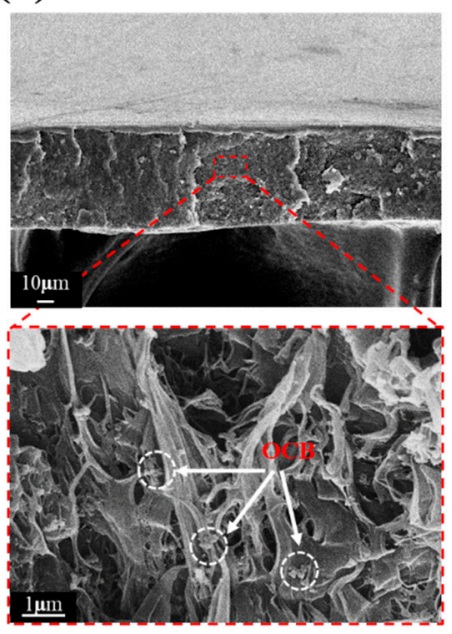

(b)

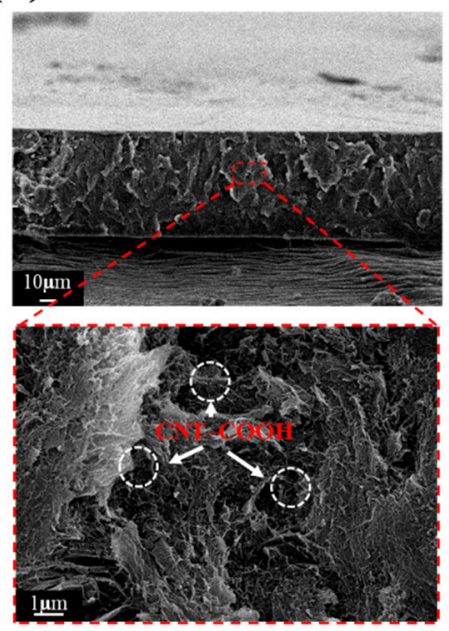

(c)

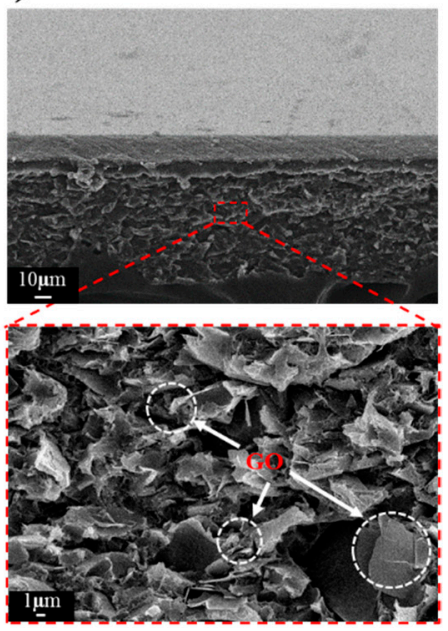

Figure 4. Scanning electron microscopy (SEM) cross-sectional images of the piezoelectric composite films: (a) OCB/PVDF-T 1 wt \%, (b) CNT-COOH/PVDF-T 1 wt \%, and (c) GO/PVDF-T $3 w t \%$.

The crystallinity of the $\beta$-phase was then calculated according to the Beer-Lambert Law, and the results are shown in Table 2 . The optimal addition amounts of the three nanocarbon materials were $1 \mathrm{wt} \%$ for OCB, $1 \mathrm{wt} \%$ for $\mathrm{CNT}-\mathrm{COOH}$, and $3 \mathrm{wt} \%$ for GO, and the $\beta$-phase crystallinity for these additions were $80.9 \%, 82.8 \%$, and $77.3 \%$, respectively. After the optimal addition amounts for each carbon nanomaterial were identified, the piezoelectric coefficients $\left(\mathrm{d}_{33}\right)$ in the $\mathrm{z}$-axis direction were measured for the three different nanocarbon/PVDF-T composite films, and the results are summarized in Table 2. The $\mathrm{d}_{33}$ of OCB/PVDF-T $1 \mathrm{wt} \%, \mathrm{CNT}-\mathrm{COOH} / \mathrm{PVDF}-\mathrm{T} 1 \mathrm{wt} \%$, and GO/PVDF-T $3 \mathrm{wt} \%$ were $23.2 \pm 1.4,24.3 \pm 1.3$, and $20.6 \pm 1$, respectively. The overall results (XRD, FTIR, and piezoelectric coefficients) showed that CNT-COOH/PVDF-T at $1 \mathrm{wt} \%$ exhibited the greatest crystallinity and piezoelectric effect. This may be attributed to the similarity in the one-dimensional structure of carbon nanotubes and the molecular chain of the $\beta$-phase of PVDF-TrFE, and as a result of this similarity, it was easier for hydrogen bonds to form between the fluorine atoms in the PVDF-TrFE molecular 
chain and the hydrogen atoms on the surface of the carbon nanotubes, thereby promoting the $\alpha$ - to $\beta$-phase transformation.

\subsection{Dispersion Stability of CNT-COOH Using Polymeric Dispersant}

The polymeric dispersant was made by combining four different styrene maleic anhydride copolymers (SMA 2000, SMA 1000, SMA EF40, and SMA EF80) with polyether monoamine (Jeffamine M1000) in different ratios at $25^{\circ} \mathrm{C}$ to prepare styrene maleic acid-amide (SMAz-M), a dendritic lipophilic polymeric dispersant; the differences in the number of benzene rings were harnessed to examine the dispersion of $\mathrm{CNT}-\mathrm{COOH}$ in the solvent with different dispersants. The chemical reaction of the polymeric dispersants is shown in Figure S4, and the reaction process was monitored using FTIR, as shown in Figure S5. The FTIR bands at $3093-2848 \mathrm{~cm}^{-1}$ and $1495-1450 \mathrm{~cm}^{-1}$ are assigned to $=\mathrm{C}-\mathrm{H}$ and $C=C$ stretching of aromatic benzene ring, respectively. The anhydride $(C=O)$ stretching vibration peaks of SMA EF40 occur at $1855 \mathrm{~cm}^{-1}$ and $1780 \mathrm{~cm}^{-1}$ [31]. After the amination reaction, the anhydride stretching vibration peak disappeared in the FTIR spectrum of SMAEF40-M, while the classical amide absorption peaks (-CONH) appeared at $1652 \mathrm{~cm}^{-1}$ and $1550 \mathrm{~cm}^{-1}$. In addition, at a frequency of $3726-3130 \mathrm{~cm}^{-1}$, a broad peak at the $-\mathrm{OH}$ stretching vibration peak of carboxylic acid appears, indicating that SMA EF40 and Jeffamine M1000 completed the amide reaction, and a similar change in FTIR was consistent with previous reports [30]. Figure 5a shows the mechanism by which the polymeric dispersant improves the dispersion and stability of modified carbon nanotubes (CNT-COOH). Both the lipophilic benzene ring of the dispersant and the aromatics on the modified carbon nanotubes engage in $\pi-\pi$ stacking. Additionally, lone pair interactions exist between the $\mathrm{CNT}-\mathrm{COOH}$ and the dispersant. These intermolecular interactions serve to increase the spacing between the carbon nanotubes, thereby restraining their agglomeration. Furthermore, the good solubility of the organic dispersants in solvents can be harnessed to enhance the dispersion and stability of carbon nanomaterials in solvents [24]. CNT-COOH was dispersed in a solvent mixed with a polymeric dispersant; the mixed solutions contained different weight ratios (10:1, 5:1, 1:1, 1:5, and 1:10) of CNT-COOH to polymeric dispersant. A transmittance analysis of the UV-Vis spectrum revealed that the absorption peak of CNT-COOH occurred at a wavelength of $550 \mathrm{~nm}$; therefore, the wavelength of $550 \mathrm{~nm}$ was used in the UV-Vis spectrum to analyze the transmittance of the CNT-COOH dispersion. The lower the transmittance, the more difficult it is for light to penetrate the sample solution; thus, the dispersion effect is improved when the transmittance is low. According to the results shown in Figure $5 b$, the best CNT-COOH:SMAz-M ratios for z = SMA2000-M, SMA1000-M, SMAEF40-M, and SMAEF80-M were $5: 1,1: 1,1: 1$, and 5:1, respectively. Figure $5 c$ presents the TEM images of CNT-COOH with no dispersants and with the four dispersants in the best ratio, confirming that the carbon nanotubes without added polymeric dispersants were prone to serious agglomeration and that agglomeration was reduced when a polymeric dispersant was added. This is because the addition of dispersant increased the spacing between the carbon nanotubes, thereby stabilizing the carbon nanotube dispersion. The SMAEF40-M carbon nanotube solution exhibited the best dispersion effect; in the TEM images, the carbon nanotubes were linear with almost no agglomeration and the number of dark black spots was low, indicating that carbon tube clustering was restrained. Additionally, the transmittance analysis and TEM images indicated that the dispersion effect of SMAEF40-M was greatest when the CNT-COOH to SMAEF40-M ratio was 1:1. 
(a)

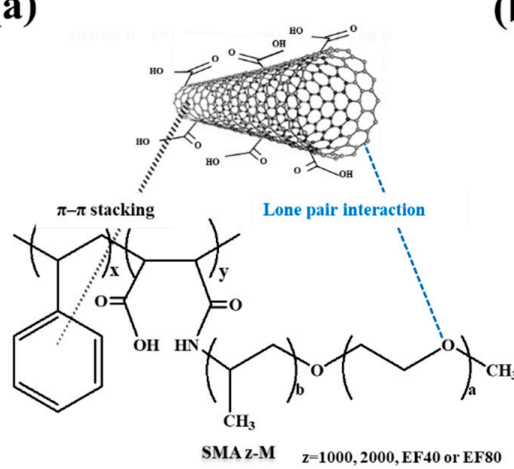

(c) (b) (1)
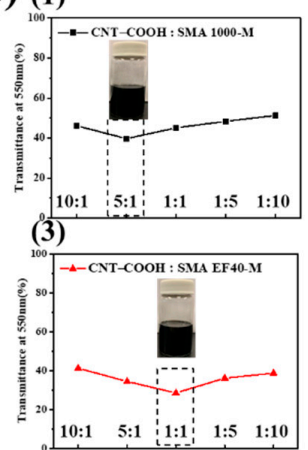

(2)

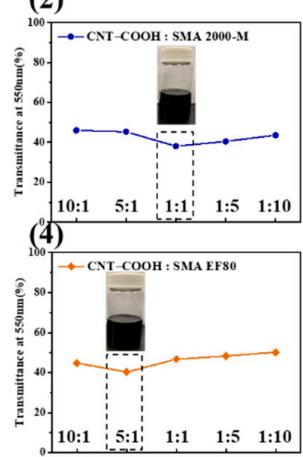

(1)

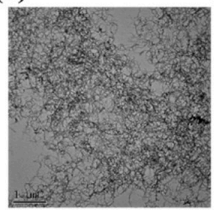

(2)

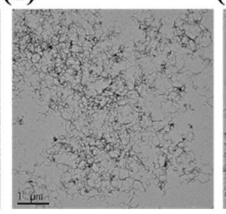

(3)

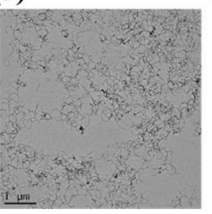

(4)

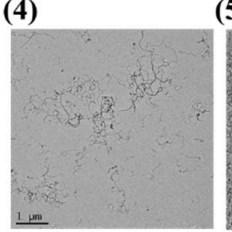

(5)

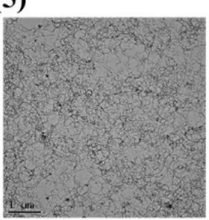

Figure 5. (a) Schematic of the dispersion mechanism of $\mathrm{CNT}-\mathrm{COOH}$ by polymeric dispersant. (b) Transmittance of CNT-COOH with different polymeric dispersants in different proportions at a wavelength of $550 \mathrm{~nm}$. (c) TEM images of (1) no polymeric dispersant added, (2) CNT-COOH:SMA1000-M 5:1, (3) CNT-COOH:SMA2000-M 1:1, (4) CNT-COOH:SMAEF40-M 1:1, (5) CNT-COOH:SMAEF80-M 5:1.

\subsection{CNT-COOH:SMAz-M/PVDF-T Piezoelectric Composite Film}

Figure 6a shows a schematic diagram of the intermolecular forces acting on the polymeric dispersant in CNT-COOH/PVDF-T. In addition to $\pi-\pi$ stacking between the polymeric dispersant and the modified carbon nanotubes $(\mathrm{CNT}-\mathrm{COOH})$ and the interaction of lone pairs of electrons, the fluorine atoms in PVDF-TrFE could simultaneously form separate hydrogen bonds with the polymeric dispersant and CNT-COOH. Thus, via these intermolecular forces, the polymeric dispersant disperses and stabilizes CNT-COOH and also concurrently induces the formation of the $\beta$-phase in PVDF-TrFE. Therefore, the four different polymeric dispersants were added to $1 \mathrm{wt} \% \mathrm{CNT}-\mathrm{COOH} / \mathrm{PVDF}-\mathrm{T}$ at the optimal ratio, and the resulting crystallinity was measured. Figure $6 b, c$ respectively show the XRD patterns and FTIR spectra of CNT-COOH:SMAz-M/PVDF-T at the optimal ratio; the calculated crystallinity and $\beta$-phase percentage are summarized in. The addition of the polymeric dispersant had no obvious effect on the crystallinity of the CNT-COOH/PVDF-T film; the crystallinity was approximately $83.5 \%$ with the dispersants and $83.4 \%$ without the dispersant. In terms of the $\beta$-phase content, the highest percentage (86.4\%) was observed for 1:1 CNT-COOH:SMA40-M/PVDF-T, which increased from $82.8 \%$ for $\mathrm{CNT}-\mathrm{COOH} / \mathrm{PVDF}-\mathrm{T}$, confirming that the dispersibility of the $\mathrm{CNT}-\mathrm{COOH} / \mathrm{PVDF}-\mathrm{T}$ composite piezoelectric film is correlated with the peak value of the $\beta$-phase of the film. If the dispersion improves, the $\mathrm{OH}$ groups in $\mathrm{CNT}-\mathrm{COOH}$ can more effectively form hydrogen bonds with the fluorine atoms in the PVDF-TrFE molecular chain. Therefore, the original $\alpha$-phase molecular chain will transform more effectively into the $\beta$-phase to produce a piezoelectric effect. The piezoelectric coefficient $\left(\mathrm{d}_{33}\right)$ of CNT-COOH:SMAEF40-M/PVDF-T 1:1 was determined and compared in Table 2, and the results showed that $\mathrm{d}_{33}$ increased from $24.3 \pm 1.3 \mathrm{pC} / \mathrm{N}$ to $26.4 \pm 1.3 \mathrm{pC} / \mathrm{N}$ with the addition of the polymeric dispersant, indicating that the polymeric dispersant effectively improved the piezoelectric property of the CNT-COOH/PVDF-T composite piezoelectric film. Subsequently, the water contact angle, Raman spectroscopy, and continuous output voltages of the CNT-COOH:SMA EF40-M/PVDF-T composite piezoelectric film with the highest $\beta$-phase crystallinity, CNT-COOH/PVDF-T, and PVDF-TrFE were compared under the same annealing temperature and polarization conditions. Figure S6 displays the water contact angle of the various piezoelectric 
films. The results revealed the water contact angles of PVDF-TrFE, CNT-COOH/PVDF-T $1 \mathrm{wt} \%$, and CNT-COOH:SMA EF40-M/PVDF-T 1:1 were 80.9, 100.9, and $107.2^{\circ}$. The results indicated that the contact angle to water has a significant upward trend when CNT-COOH was added to PVDF-TrFE because the carbon nanomaterials are distributed on the surface of PVDF-TrFE when PVDF-TrFE was added with $\mathrm{CNT}-\mathrm{COOH}$, thereby increasing the surface roughness, which has been reported in previous studies [32,33]. Subsequently, it can be found that the water contact angle increased from 100.9 to $107.2^{\circ}$ by adding SMA EF40-M, which may be because SMA EF40-M can improve $\mathrm{CNT}-\mathrm{COOH}$ dispersal in PVDF-TrFE. Therefore, CNT-COOH was more uniformly dispersed on the surface of PVDF-TrFE and promoted an increase in the contact angle to water. To confirm the effect of SMA-EF40 on CNT-COOH in PVDF-TrFE film, Figure S7 displays the Raman spectroscopy of CNT-COOH/PVDF-T $1 \mathrm{wt} \%$ and CNT-COOH:SMA EF40-M/PVDF-T 1:1. The results revealed that the D Band red shifted from 1346.7 to 1346.2 and the G Band red shifted from 1590.0 to 1586.2 when SMA EF40-M was added to CNT-COOH/PVDF-T $1 \mathrm{wt} \%$, There have been reports that have indicated that a red shift phenomenon occurs in the Raman spectrum when CNTs adsorb specific molecules [34], therefore, this phenomenon confirms that a certain interaction was found between SMA EF40-M and $\mathrm{CNT}-\mathrm{COOH}$ and further promotes the uniform dispersion of CNT-COOH in the PVDF-TrFE film when SMA EF40-M is added to CNT-COOH/PVDF-T $1 \mathrm{wt} \%$. The continuous output voltage under pressure was measured using the compression mold of a universal stretching machine, and the spectrum generated by the computer and the oscilloscope is shown in Figure 6d. Different compression strengths were applied and the continuous voltage outputs were recorded; the results are shown in Figure 6e and the data sorted in Table 3. The results showed that pure PVDF-TrFE without additives exhibited poor piezoelectric effect; when the pressure was $200 \mathrm{~N}$, the average voltage of CNT-COOH:SMA EF40-M/PVDF-T was $1.36 \mathrm{~V}$, and the maximum voltage was $1.57 \mathrm{~V}$. When the applied pressure was $400 \mathrm{~N}$, the average voltage reached $2.36 \mathrm{~V}$ and the maximum voltage was $2.72 \mathrm{~V}$, representing an increase of $9 \%$ compared with the average voltage of $2.16 \mathrm{~V}$ and the maximum voltage of $2.50 \mathrm{~V}$ of the CNT-COOH/PVDF-T film without a dispersant. Therefore, by improving the dispersibility of the $\mathrm{CNT}-\mathrm{COOH}$ solution, the enhanced intermolecular interactions between the - $\mathrm{COOH}$ groups on the surface of CNT-COOH and the fluorine atoms of PVDF-TrFE promoted a higher proportion of the PVDF-TrFE molecular chain to convert from the $\alpha$-phase to the $\beta$-phase, thereby increasing the output voltage of the film.

\subsection{Application of the CNT-COOH:SMAEF40-M/PVDF-T Piezoelectric Composite Film}

According to the results of the above experiments, the CNT-COOH:SMA EF40-M/PVDF-T piezoelectric composite film exhibited good piezoelectric effect, and thus was applied to several devices. In the seismocardiographic application, the small vibrations generated by the movements of the heart's aortic valve, mitral valve, and myocardium were converted by the piezoelectric composite film into electrical energy to produce physiological signals. Figure 7a shows the structural design of the seismocardiographic sensor; the black area in the middle is the piezoelectric film and the blue area is the platinum-plated conductive layer. The outermost layer used $3 \mathrm{M}$ medical tape as an insulating layer that tightly fit onto the body. Figure $7 \mathrm{~b}$ shows the three different positions of the film for the seismocardiographic measurements. The red frame indicates the upper part of the pectoralis major muscle near the shoulders, the green frame covers the middle position near the inner side of the pectoralis major muscle, and the blue frame is positioned at the lower edge of the pectoralis major. The seismocardiographs measured at the three different locations are shown in Figure 7c,d for comparison; the upper (red) seismocardiograph was located relatively far from the heart, and consequently, the signal had the most noise and no obvious characteristic peaks; the lower (blue) signal was relatively stable, but there were no obvious atrial valve opening $(\mathrm{AO})$ and mitral valve opening $(\mathrm{MO})$ characteristic peaks; the middle (green) seismocardiographic signal was the most stable and had four distinct characteristic peaks, namely mitral valve opening and closing $(\mathrm{MC}, \mathrm{MO})$ and aortic valve opening and closing $(\mathrm{AO}, \mathrm{AC})$. According to 
these results, the CNT-COOH:SMAEF40-M/PVDF-T piezoelectric composite film can be applied to the seismocardiographic sensor. The CNT-COOH:SMAEF40-M/PVDF-T piezoelectric composite film was also used in this study to fabricate a pressure sensor, as shown in Figure 7e. The counterforce from a punch using the boxing glove was harnessed to generate a voltage, and the force of the punch could be calculated through the magnitude of the voltage. This application of the film in a pressure sensor generated considerable sensitivity and output response; furthermore, by using PET film as packaging, the mechanical strength of the film was improved. After continuous punches, the film was not damaged and still delivered good responses. Figure $7 \mathrm{f}$ shows the voltage generated by the boxing glove continuously beating against the wall, revealing that the maximum voltage can be as high as $4.8 \mathrm{~V}$. Finally, the piezoelectric composite film was used to prepare energy harvesting elements, as shown in Figure 7g. The CNT-COOH:SMAEF40-M/PVDF piezoelectric composite film was used as a coating on shoes to prepare piezoelectric footwear to collect the voltage generated during walking, which can be stored in an energy storage device. This device can be applied to hiking shoes, snow boots, etc. to provide Global Positioning System (GPS) positioning or send distress signals and to other equipment to provide emergency power. Figure $7 \mathrm{~h}$ shows the voltages generated by the piezoelectric shoes worn by an adult weighing $65 \mathrm{~kg}$, where the maximum voltage generated was $4.8 \mathrm{~V}$. (Video S1 demonstrates the actual operation of the pressure sensing element). In summary, the CNT-COOH:SMAEF40-M/PVDF-T piezoelectric composite film was successfully applied in a seismocardiographic sensor, a pressure sensor, and an energy harvesting device, demonstrating the considerable commercial potential of the film.
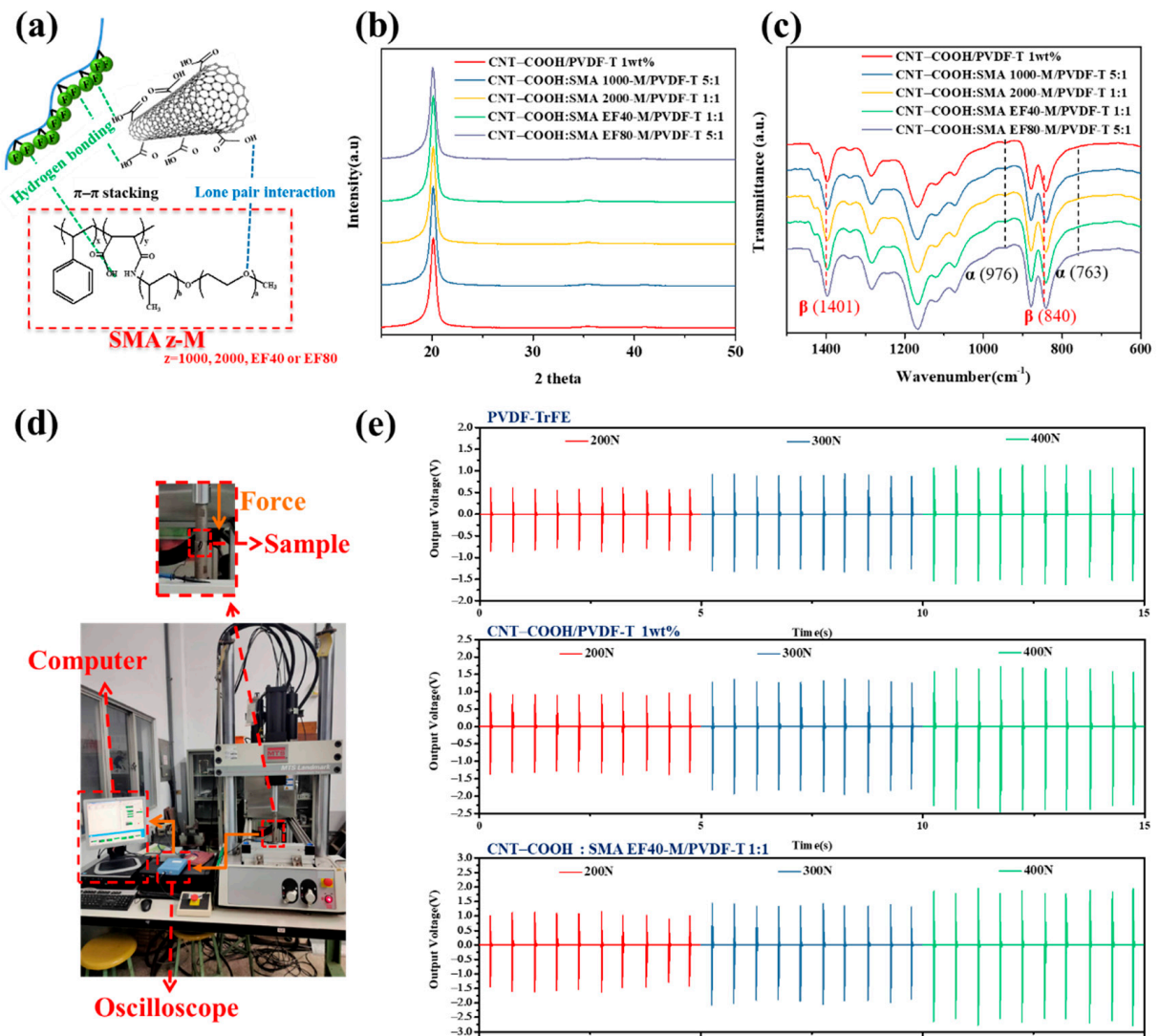

(e)
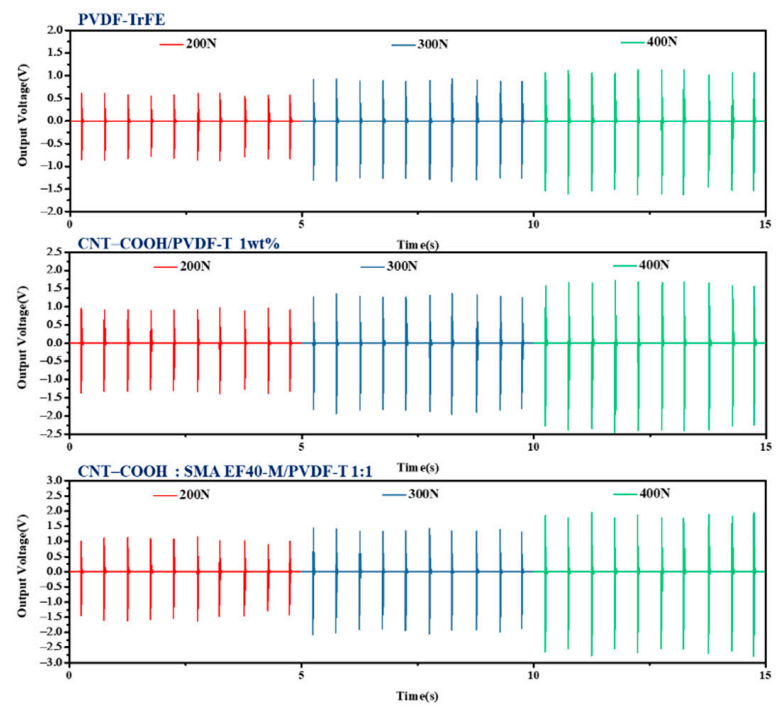

Figure 6. (a) Schematic of the polymeric dispersant interacting with CNT-COOH and PVDF-TrFE. (b) XRD and (c) FTIR curves of CNT-COOH:SMAzM/PVDF-T with different polymeric dispersants at the optimal ratio. (d) Photograph of continuous output voltage test setup and (e) the continuous output voltage curve of PVDF-TrFE, $1 \mathrm{wt} \%$ CNT-COOH/PVDF-T, and 1:1 CNT-COOH:SMA EF40-M/PVDF-T under different pressures. 
Table 3. Continuous output voltage results of PVDF-TrFE, CNT-COOH/PVDF-T $1 \mathrm{wt} \%$, and CNT-COOH:SMA EF40-M/PVDF-T 1:1.

\begin{tabular}{ccccccc}
\hline & \multicolumn{2}{c}{$\mathbf{2 0 0} \mathbf{~ N}$} & \multicolumn{2}{c}{$\mathbf{3 0 0} \mathbf{~ N}$} & \multicolumn{2}{c}{$\mathbf{4 0 0 ~ \mathbf { ~ }}$} \\
\cline { 2 - 7 } Sample Name & $\begin{array}{c}\text { Max } \\
\text { Voltage (V) }\end{array}$ & $\begin{array}{c}\text { Avg. } \\
\text { Voltage (V) }\end{array}$ & $\begin{array}{c}\text { Max } \\
\text { Voltage (V) }\end{array}$ & $\begin{array}{c}\text { Avg. } \\
\text { Voltage (V) }\end{array}$ & $\begin{array}{c}\text { Max } \\
\text { Voltage (V) }\end{array}$ & $\begin{array}{c}\text { Avg. } \\
\text { Voltage (V) }\end{array}$ \\
\hline PVDF-TrFE & 0.96 & 0.71 & 1.32 & 1.04 & 1.66 & 1.31 \\
CNT-COOH/PVDF-T 1 wt $\%$ & 1.46 & 1.22 & 1.98 & 1.61 & 2.50 & 2.16 \\
CNT-COOH:SMA & 1.57 & 1.34 & 2.06 & 1.75 & 2.72 & 2.36 \\
EF40-M/PVDF-T 1:1 & & & & & &
\end{tabular}

(a)

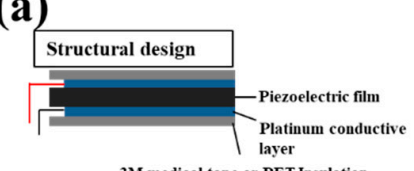

(b)

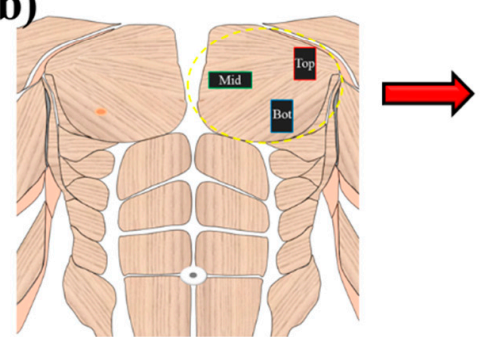

(e)

(g)

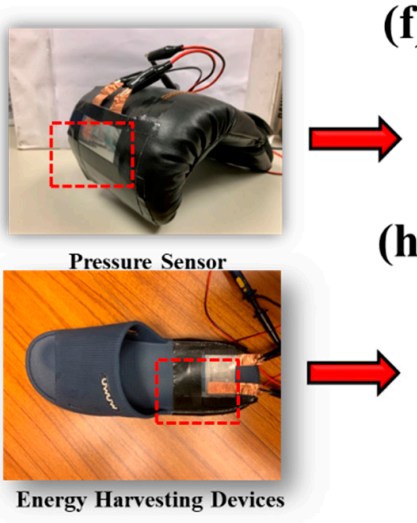

(c)

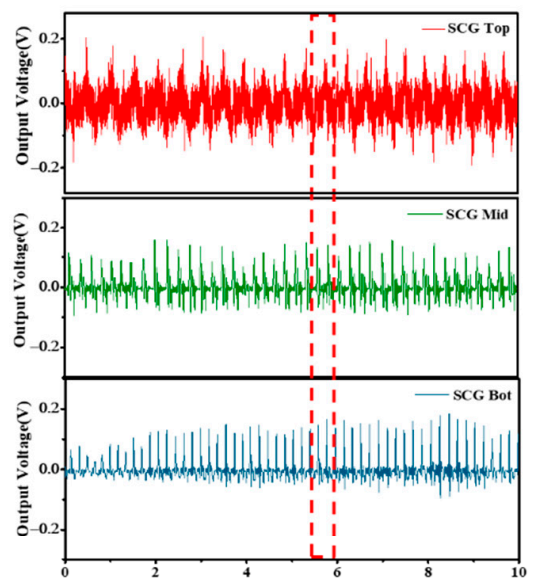

(d)

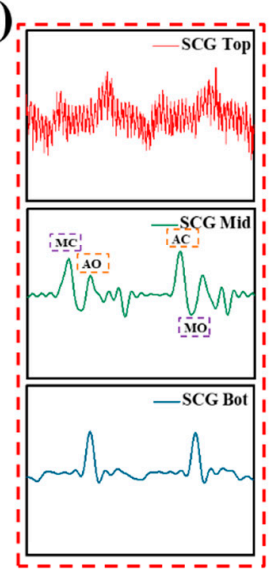

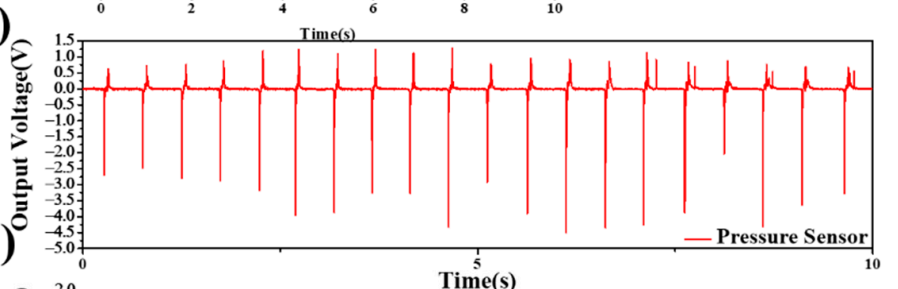

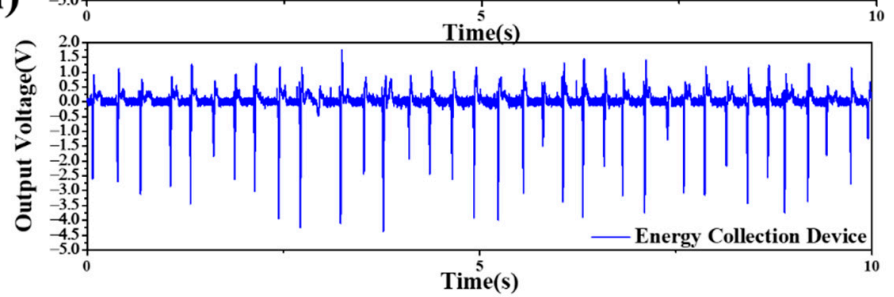

Figure 7. (a) Schematic of the CNT-COOH:SMA EF40-M/PVDF-T packaged sensing element, (b) schematic of the seismocardiography measurement positions, (c) measurement seismocardiography curves at different positions, and (d) partial enlarged view of the seismocardiography measurement at different positions. (e) Schematic of the pressure sensor and (f) measurement curves of the pressure sensor. (g) Schematic of the energy collector and (h) measurement curves of the energy collector.

\section{Conclusions}

This study successfully used carbon nanotubes of different dimensions to enhance the crystallinity and $\beta$-phase content of PVDF-TrFE for improing the piezoelectric effect of the composite film. The experimental results revealed that modified carbon nanotubes greatly improved the piezoelectric effect of the film. As carbon materials are prone to agglomeration, polymeric dispersants were added to increase the dispersibility of the carbon materials in PVDF-TrFE; moreover, van der Waals forces were exploited to inhibit the stacking and agglomeration of carbon nanomaterials, thereby improving the dispersibility and stability of the carbon materials in organic solvents. The developed composite films also successfully achieved a high voltage of $2.7 \mathrm{~V}$ under an applied pressure of $400 \mathrm{~N}$, which was finally applied to seismocardiographic (SCG) sensors, pressure sensors, and energy harvesting elements. In SCG physiological signal sensing, there were obvious characteristic peaks in the seismogram obtained 
by measuring physiological signals such as the contraction of heart valves and myocardium. In the case of the pressure sensor, the voltage generated by the counterforce from a punch with the boxing glove can be used to calculate the force of the punch, where the maximum voltage reached $4.8 \mathrm{~V}$. Finally, the energy harvesting element can be used in hiking shoes to store the voltage generated during walking for emergency use, where the maximum voltage was $4.8 \mathrm{~V}$. The results indicate that as a result of the van der Waals forces, the $\beta$-phase content of the CNT-COOH:SMAEF40-M/PVDF-T piezoelectric composite film increased from $73.6 \%$ to $86.4 \%$, which in turn increased the piezoelectric coefficient from $19.8 \pm 1.0$ to $26.4 \pm 1.3 \mathrm{pC} / \mathrm{N}$. This composite film, with its good piezoelectric coefficient, obtained satisfactory performance in three applications, which is ample evidence of the great commercial potential of the CNT-COOH:SMAEF40-M/PVDF-T piezoelectric composite film.

Supplementary Materials: The following are available online at http://www.mdpi.com/2073-4360/12/12/2999/s1, Figure S1: (a) FTIR curves of PVDF-TrEE polarization at different voltages, (b) hysteresis curve of PVDF-TrEE after annealing treatment at $145^{\circ} \mathrm{C}$, Figure S2: FTIR curves of carbon nanomaterials before and after oxidation: (a) CB, (b) CNT, and (c) GO, Figure S3: DSC (a) cooling and (b) heating curves of PVDF-TrEE and the different carbon nanomaterial/PVDF-T, Figure S4: Schematic diagram illustrating the chemical reaction of the polymeric dispersant, Figure S5: FT-IR spectra of the (a) SMA EF40 and (b) SMA EF40-M polymeric dispersants, Figure S6: The water contact angle of PVDF-TrEE, CNT-COOH/PVDF-T $1 \mathrm{wt} \%$ and CNT-COOH:SMA EF40-M/PVDF-T 1:1, Figure S7: The Raman spectroscopy of PVDF-TrEE, CNT-COOH/PVDF-T $1 \mathrm{wt} \%$ and CNT-COOH:SMA EF40-M/PVDF-T 1:1.

Author Contributions: Conceptualization, C.-Y.H., J.-X.C., X.-Y.H., Y.-F.C. and C.-F.J.K.; Data curation, J.-W.L., C.-Y.H., K.-Y.C., J.-X.C., X.-Y.H. and C.-F.J.K.; Formal analysis, J.-W.L., C.-Y.H., K.-Y.C. and Y.-F.C.; Software, J.-W.L. and K.-Y.C.; Supervision, C.-W.C.; Writing-original draft, J.-W.L., K.-Y.C. and C.-W.C.; Writing-review \& editing, C.-F.J.K., C.-C.C., M.-C.S. and C.-W.C. All authors have read and agreed to the published version of the manuscript.

Funding: This research was funded by the Ministry of Science and Technology (MOST 108-2221-E-011-042-MY2) of Taiwan.

Conflicts of Interest: The authors declare no conflict of interest.

\section{References}

1. Zhao, X.; Yang, S.; Sun, Z.; Cui, N.; Zhao, P.; Tang, Q.; Tong, Y.; Liu, Y. Enhancing the intrinsic stretchability of micropatterned gold film by covalent linkage of carbon nanotubes for wearable electronics. ACS Appl. Electron. Mater. 2019, 1, 1295-1303. [CrossRef]

2. Al-Milaji, K.N.; Huang, Q.; Li, Z.; Ng, T.N.; Zhao, H. Direct embedment and alignment of silver nanowires by inkjet printing for stretchable conductors. ACS Appl. Electron. Mater. 2020, 2, 3289-3298. [CrossRef]

3. Meng, Y.; Zhang, X.; Ma, Y.; Feng, X. Stretchable self-powered generator for multiple functional detection. ACS Appl. Electron. Mater. 2020, 2, 3577-3584. [CrossRef]

4. Gielen, D.; Boshell, F.; Saygin, D.; Bazilian, M.D.; Wagner, N.; Gorini, R. The role of renewable energy in the global energy transformation. Energy Strat. Rev. 2019, 24, 38-50. [CrossRef]

5. Bardineh, Y.H.; Mohamadian, F.; Ahmadi, M.H.; Akbarianrad, N. Medical and dental applications of renewable energy systems. Int. J. Low-Carbon Technol. 2018, 13, 320-326. [CrossRef]

6. Zhang, X.; Pan, H.; Qi, L.; Zhang, Z.; Yuan, Y.; Liu, Y. A renewable energy harvesting system using a mechanical vibration rectifier (MVR) for railroads. Appl. Energy 2017, 204, 1535-1543. [CrossRef]

7. Khan, F.U.; Qadir, M.U. State-of-the-art in vibration-based electrostatic energy harvesting. J. Micromech. Microeng. 2016, 26, 103001. [CrossRef]

8. Sharma, H.B.; Sarma, H.N.K.; Mansingh, A. Ferroelectric and dielectric properties of sol-gel processed barium titanate ceramics and thin films. J. Mater. Sci. 1999, 34, 1385-1390. [CrossRef]

9. Ponnamma, D.; Chamakh, M.M.; Alahzm, A.M.; Salim, N.V.; Hameed, N.; Al-Maadeed, M. Core-shell nanofibers of polyvinylidene fluoride-based nanocomposites as piezoelectric nanogenerators. Polymers 2020, 12, 2344. [CrossRef]

10. Benz, M.; Euler, W.B. Determination of the crystalline phases of poly(vinylidene fluoride) under different preparation conditions using differential scanning calorimetry and infrared spectroscopy. J. Appl. Polym. Sci. 2003, 89, 1093-1100. [CrossRef]

11. Zhang, Q.M.; Bharti, V.; Zhao, X. Giant Electrostriction and relaxor ferroelectric behavior in electron-irradiated poly(vinylidene fluoride-trifluoroethylene) copolymer. Science 1998, 280, 2101-2104. [CrossRef] [PubMed] 
12. Kaczmarek, H.; Królikowski, B.; Chylińska, M.; Klimiec, E.; Bajer, D. Piezoelectric films based on polyethylene modified by aluminosilicate filler. Polymers 2019, 11, 1345. [CrossRef] [PubMed]

13. Fortunato, M.; Cavallini, D.; De Bellis, G.; Marra, F.; Tamburrano, A.; Sarto, M.S. Phase inversion in PVDF films with enhanced piezoresponse through spin-coating and quenching. Polymers 2019, 11, 1096. [CrossRef] [PubMed]

14. Wu, D.; Wang, J.; Zhang, M.; Zhou, W. Rheology of carbon nanotubes-filled poly(vinylidene fluoride) composites. Ind. Eng. Chem. Res. 2012, 51, 6705-6713. [CrossRef]

15. Zhang, L.; Zha, D.-A.; Du, T.; Mei, S.; Shi, Z.; Jin, Z. Formation of superhydrophobic microspheres of poly(vinylidene fluoride- hexafluoropropylene)/graphene composite via gelation. Langmuir 2011, 27, 8943-8949. [CrossRef]

16. Abdolmaleki, H.; Agarwala, S. PVDF-BaTiO 3 nanocomposite inkjet inks with enhanced $\beta$-phase crystallinity for printed electronics. Polymers 2020, 12, 2430. [CrossRef]

17. Singh, D.; Choudhary, A.; Garg, A. Flexible and robust piezoelectric polymer nanocomposites based energy harvesters. ACS Appl. Mater. Interfaces 2018, 10, 2793-2800. [CrossRef]

18. Xu, P.; Fu, W.; Cui, Z.; Ding, Y. Synergistic promotion of polar phase crystallization of PVDF by ionic liquid with PEG segment. Appl. Surf. Sci. 2018, 444, 480-484. [CrossRef]

19. Karan, S.K.; Mandal, D.; Khatua, B.B. Self-powered flexible Fe-doped RGO/PVDF nanocomposite: An excellent material for a piezoelectric energy harvester. Nanoscale 2015, 7, 10655-10666. [CrossRef]

20. Shuai, C.; Zeng, Z.; Yang, Y.-W.; Qi, F.; Peng, S.; Yang, W.; He, C.; Wang, G.; Qian, G. Graphene oxide assists polyvinylidene fluoride scaffold to reconstruct electrical microenvironment of bone tissue. Mater. Des. 2020, 190, 108564. [CrossRef]

21. Bhavanasi, V.; Kumar, V.; Parida, K.; Wang, J.; Lee, P.S. Enhanced piezoelectric energy harvesting performance of flexible PVDF-TrFE bilayer films with graphene oxide. ACS Appl. Mater. Interfaces 2016, 8, 521-529. [CrossRef] [PubMed]

22. Levi, N.; Czerw, R.; Xing, S.; Iyer, P.; Carroll, D.L. Properties of polyvinylidene difluoride-carbon nanotube blends. Nano Lett. 2004, 4, 1267-1271. [CrossRef]

23. Pariy, I.O.; Ivanova, A.A.; Shvartsman, V.V.; Lupascu, D.C.; Sukhorukov, G.B.; Ludwig, T.; Bartasyte, A.; Mathur, S.; Surmenev, R.A.; Surmenev, R.A. Piezoelectric response in hybrid micropillar arrays of poly(vinylidene fluoride) and reduced graphene oxide. Polymers 2019, 11, 1065. [CrossRef] [PubMed]

24. Chiu, C.-W.; Ou, G.-B. Facile preparation of highly electrically conductive films of silver nanoparticles finely dispersed in polyisobutylene-b-poly(oxyethylene)-b-polyisobutylene triblock copolymers and graphene oxide hybrid surfactants. RSC Adv. 2015, 5, 102462-102468. [CrossRef]

25. Chiu, C.-W.; Lin, C.-A.; Hong, P.-D. Melt-spinning and thermal stability behavior of $\mathrm{TiO}_{2}$ nanoparticle/polypropylene nanocomposite fibers. J. Polym. Res. 2010, 18, 367-372. [CrossRef]

26. Huang, P.-Y.; Chiu, C.-W.; Huang, C.-Y.; Shen, S.-Y.; Lee, Y.-C.; Cheng, C.-C.; Jeng, R.-J.; Lin, J.-J. Facile fabrication of flexible electrodes and immobilization of silver nanoparticles on nanoscale silicate platelets to form highly conductive nanohybrid films for wearable electronic devices. Nanomaterials 2019, 10, 65. [CrossRef]

27. Lee, Y.-C.; Chiu, C.-W. Immobilization and 3D hot-junction formation of gold nanoparticles on two-dimensional silicate nanoplatelets as substrates for high-efficiency surface-enhanced Raman scattering detection. Nanomaterials 2019, 9, 324. [CrossRef]

28. Barretta, R.; De Sciarra, F.M. Variational nonlocal gradient elasticity for nano-beams. Int. J. Eng. Sci. 2019, 143, 73-91. [CrossRef]

29. Barretta, R.; Caporale, A.; Faghidian, S.A.; Luciano, R.; De Sciarra, F.M.; Medaglia, C.M. A stress-driven local-nonlocal mixture model for Timoshenko nano-beams. Compos. Part B Eng. 2019, 164, 590-598. [CrossRef]

30. Chiu, C.-W.; Li, J.-W.; Huang, C.-Y.; Yang, S.-S.; Soong, Y.-C.; Lin, C.-L.; Lee, J.C.-M.; Sanchez, W.A.L.; Cheng, C.-C.; Suen, M.-C. Controlling the structures, flexibility, conductivity stability of three-dimensional conductive networks of silver nanoparticles/carbon-based nanomaterials with nanodispersion and their application in wearable electronic sensors. Nanomaterials 2020, 10, 1009. [CrossRef]

31. Arat, R.; Uyanık, N. Study of the morphological and thermal properties of polystyrene nanocomposites based on modified halloysite nanotubes with styrene-maleic anhydride copolymers. Mater. Today Commun. 2017, 13, 255-262. [CrossRef] 
32. Li, J.-W.; Tsen, W.-C.; Tsou, C.-H.; Suen, M.-C.; Chiu, C.-W. Synthetic environmentally friendly castor oil based-polyurethane with carbon black as a microphase separation promoter. Polymers 2019, 11, 1333. [CrossRef] [PubMed]

33. Sun, J.-T.; Li, J.-W.; Tsou, C.-H.; Pang, J.-C.; Chung, R.-J.; Chiu, C.-W. Polyurethane/nanosilver-doped halloysite nanocomposites: Thermal, mechanical properties, and antibacterial properties. Polymers 2020, 12, 2729. [CrossRef] [PubMed]

34. Yin, Y.; Ma, L.; Wen, S.; Luo, J. Fracture of the intermolecular hydrogen bond network structure of glycerol modified by carbon nanotubes. J. Phys. Chem. C 2018, 122, 19931-19936. [CrossRef]

Publisher's Note: MDPI stays neutral with regard to jurisdictional claims in published maps and institutional affiliations.

(C) 2020 by the authors. Licensee MDPI, Basel, Switzerland. This article is an open access article distributed under the terms and conditions of the Creative Commons Attribution (CC BY) license (http://creativecommons.org/licenses/by/4.0/). 